\title{
WhatsApp Application in English Language Teaching (ELT) Context: Media to Describe People
}

\author{
Syarifah Afsyah \\ Universitas Lancang Kuning, Pekanbaru, Indonesia \\ syarifahafsyah3@gmail.com
}

\section{ARTICLE HISTORY}

Received : 2019-05-31

Revised : 2019-06-01

Accepted : 2019-06-20

\section{KEYWORDS}

WhatsApp

Vocabulary

Teaching English

Describing people

\begin{abstract}
Learning media is a vehicle and delivery of information or learning messages to students who can help teachers improve student achievement. Learning media always develops, along with technological developments. This study aims to analyze the function of learning media using WhatsApp in learning material describing people can support improving vocabulary in students that can be used in the learning process of teaching English in Senior High School. WhatsApp media can be used according to the level of student needs and material to be delivered. This type of research is a literature review by gathering sources of information and data from written documents in the form of articles, journals, and books. The conclusion of the study is the existence of the benefits of WhatsApp media that can be used by teachers for learning English in senior high school from simple material to complex material by utilizing technological developments and advancements.
\end{abstract}

\section{Introduction}

21st-century learning emphasises the ability of students to think critically, able to connect knowledge with the real world, master information technology, communicate and collaborate. Achieving these skills can be achieved by applying appropriate learning methods in terms of mastery of material and skills. In addition to choosing the right learning method, media and learning resources are also important to play a role in achieving an effective teaching and learning process.

The use of media in the learning process in school is related to the level of psychological development and the ability of students who follow the learning process and adapted to the interests and talents of students who can arouse student motivation towards learning. In conducting learning, each teacher should have learning media. Learning media is a component of learning that includes materials and equipment. With the entry of various theories and technologies, learning media continue to experience and appear in various types.

The opinions of experts suggest the use of media in the learning process can attract interest and motivate student learning (Heinich, 1996; Buchanan, 2004; Normore, 2006). According to Heinich (1996) in his book "Instructional Technology and Media for Learning" states that the media is a communication channel tool. Learning media can be said as a messenger technology used for learning purposes. Buchanan (2004) mentions online learning gives both teachers and students new opportunities to be involved in the learning process. Virtual chat, or synchronous, provides additional media for communication that is attractive to active and global social learners, abstract students. Teachers can increase student motivation in learning by giving criticism and praise comments to students through chat groups that have been made and by a predetermined agenda. In addition, Normore (2004) shows in the article, begins with an analysis of how media can be used as a teaching tool in university education leadership programs in promoting moral literacy. We argue that the star at framework is a process in which educational leaders can evolve from using ethical transactional approaches to controversial issues to using moral and transformational ways to solve problems.

Some practical uses of the use of learning media are learning media that can clarify the presentation of messages and information to facilitate and improve learning processes and outcomes. Besides learning, media can increase and direct the attention of students so that it can lead to motivation to learn, more direct interaction between students and their environment, and the possibility of students to learn independently according to their abilities and interests. Learning media can also overcome sensory limitations, space and time. 
The same is true of learning English in high school. The use of media in learning English in high school can make students do more learning activities, and other activities such as observing, doing, demonstrating, and so on. Learning English in High School aims to train students to be able to communicate orally and in writing. Communicating, in this case, is understanding and disclosing information, thoughts, feelings, and developing science, technology, and culture. Therefore, English subjects in high school are directed at developing listening, speaking, reading and writing skills so that graduates can communicate and discourse in English.

Vocabulary knowledge has always been an important component in reading and speaking learning, but interest in teaching has increased and decreased. To be able to speak English fluently and well, students must be able to master various kinds of vocabulary. So important is vocabulary mastery for students because it will improve their English skills (Fisher, 2016; Graves, 2000; Seipel, 2011; Vermeer, 2001). According to Fisher (2016) mentions that vocabulary learning occurs when students are immersed in language and words. They need to experience a language environment that is rich in words that foster word awareness, motivation to learn and help them have words from themselves.

Moreover, raves (2000) argues that the use of language and clear vocabulary makes writing more insightful and interesting, and communication becomes effective and occurs spontaneously. Otherwise, poor grammar, choice of words, and use of punctuation disrupt communication; Weak vocabulary, in particular, hurts the understanding of readers and listeners. Seipel (2011) shows that a large number of vocabularies are learned by chance from context and that informal teaching can fill the void of teaching left by inadequate time in the classroom for explicit vocabulary teaching. In addition, Vermeer (2001) argues that deeper knowledge of words is a consequence of knowing more words, because the more words a person knows, the finer the network and the deeper the knowledge. Based on the opinions of experts, it has been proven that vocabulary learning is very important regarding the development of students' English so that students can write and speak in English fluently, correctly and meaningfully.

Therefore there are some researchers who focus on the vocabulary teaching strategies for English students (Rieger, 2016; Hwang, 2011; Kruger, 2010). According to Rieger (2016) found that formal and direct teaching gave a positive role and suggested substantial benefits from informal and non-traditional approaches. And he also found that teaching grammar and vocabulary out of context and through repetition was not interesting. Therefore, he explores the potential of blogging to fifth-grade students with authentic goals and with a real audience. And he argues that by teaching students to use strong language and increasing the application of vocabulary through dialogue with the actual readers of students writing on blogs is an innovative approach to language studies that can change the situation as it is today. Hwang (2011) said that two specific aspects of vocabulary knowledge were discussed in the research literature, namely the breadth and depth of vocabulary. The area refers to the number of words known, and the depth of vocabulary refers to the quality of lexical knowledge or how well students know a word. To capture the choice of vocabulary styles, he examined all student e-mails in each period for more detailed cohesion analysis, semantic use, and derivative morphology. Kruger (2010) confirms that the use of vocabulary tests to assess the level of security awareness will be useful, and there is a significant relationship between knowledge of concepts (vocabulary) and behaviour. A series of familiar words related to information security is a person's information security vocabulary. And such vocabulary will develop over time and allow one to communicate and acquire new knowledge.

Furthermore, in teaching vocabulary to English students can also be supported by using online media or applications such as WhatsApp. Some experts have researched the effectiveness of using WhatsApp media in teaching and learning English (Kheryadi, 2017; Hamad, 2017; Ajid, 2018; Mwakapina, 2016). According to Kheryadi (2017) states that the implementation of using WhatsApp as one of the tools that are useful to help students in communicative language learning. This media can help students to build confidence and motivate them to learn. And students state that they feel confident, independent, enthusiastic, and have a positive attitude to learning English using the application, and therefore, WhatsApp is one of the latest technologies that help language teaching. Hamad (2017) also found that WhatsApp can improve student learning and enthusiasm, and help students develop English language skills, enrich their vocabulary, and learn from the mistakes of partners or members in their groups.

Ajid (2018) sees that students cannot be separated by their cellphones. They do a lot of things on their cellphones like sending text, audio messages, uploading and uploading pictures and videos or just browsing. Collaborative learning uses a collaborative tool by combining student collaboration and the use of mobile applications such as WhatsApp, which can optimize cellphone functions for student learning processes to which greatly help teachers in teaching. It can be said that the integration of WhatsApp into their education will be easy, enjoyable and useful. And students will get 
positive intentions in learning related to the use of WhatsApp in their learning process. And Mwakapina (2016) also concluded that the use of the WhatsApp Social Networking Tool (WSNT) in the Second English Language learning class (L2) would make the class more interactive. Because teaching large classes, interactively has always been the biggest challenge for a language teacher in many developing countries.

Furthermore, the use of WhatsApp to students in teaching English is very effective to use. Based on the ideas mentioned above, the focus of this article is to investigate the Use of WhatsApp in Teaching Describing People can Improve Students' Vocabulary in Senior High School, with the research question: Does the application of learning media use WhatsApp on learning materials describing people can improve vocabulary for students in senior high school?. Thus this study seeks to prove that learning media applications by using WhatsApp on learning materials describing people can improve vocabulary for students in senior high school.

\section{Methods}

This research was designed in qualitative descriptive research; Data is collected from several related kinds of literature on the application of WhatsApp media applications in English classrooms situation. Information relating to the use of WhatsApp media applications in the EFL class is collected. Then, information is presented based on WhatsApp's role, and the WhatsApp usage technique will be used in the teaching and learning process in the classroom. Both of these components are expected to represent the significant role of WhatsApp media applications in the EFL class and several ways that can be applied by EFL teachers in teaching by implementing WhatsApp media applications. Finally, some conclusions are drawn to prove the effectiveness of using WhatsApp media applications in increasing vocabulary in students used in class.

\section{Result and Discussion}

The results of this study after looking at several studies related to using the WhatsApp application as a medium for teaching and learning is that the use of the WhatsApp application has many advantages such as increasing self-confidence, enthusiasm, motivation for student learning and being proactive. When teachers use WhatsApp media applications to English classrooms to improve their vocabulary, students can become more active in speaking English on WhatsApp and increase students' learning motivation about learning material. When using the WhatsApp application, students can place themselves in a realworld conversation and get teaching from mistakes made by their partners or members in their WhatsApp group.
In addition, the teacher designs learning activities that can make students in active learner mode. In this case, the teachers are challenged to involve students actively during teaching and learning activities using the WhatsApp application. To use the WhatsApp application as a powerful tool during teaching and learning activities, material preparation is one of the main ways to make it more meaningful before applying several other ways to encourage students to become active learners.

According to Kheryadi (2017) in teaching using WhatsApp, this can also be done in two ways, namely dependent and independent conversation. Here are two ways you can use the WhatsApp application as a medium in teaching English:

\subsection{Dependent Conversation}

In the dependent conversation occurs under the guidance of the teacher, the teacher actively participates in online dialogue, and the teacher guides and participates in the conversation. The conversation situation is formal because it is guided by the teacher. In this case, the teacher's role is to motivate students to be confident to write, facilitate a group of WhatsApp, create a conversation schedule to keep students connected online, give material via WhatsApp, ask students to discuss material, ask students to answer and throwing feedback in the form of questions or comments on the answers given by students.

\subsection{Independent Conversation}

In an independent conversation, the teacher makes a WhatsApp conversation that allows students to communicate between them to discuss any ideas they want to talk about without the involvement of the teacher in the online dialogue and accordance with the material provided by the teacher. The role of the teacher, in this case, is to facilitate a group of WhatsApp, giving motivation to students to write and express their personal feelings, and monitor group members to observe whether they are active or not.

There are also various positive effects on students' progress in learning in particular, as Kheryadi (2017) stated in his article that students show their confidence, independence (autonomous), enthusiasm, and positive attitude towards learning English. Here are some positive effects that arise in students using WhatsApp in classroom learning activities:

\section{a) Confidence}

Students confirm that they are happy and comfortable using WhatsApp in learning English because with WhatsApp, they can write using English and are not afraid and ashamed to use grammar and choose the right vocabulary. Because in the WhatsApp application, they have friends and teachers 
who help them write. In the classroom, face-to- face meeting with the teacher and friends makes some passive students do not want to ask questions or even answer questions.

\section{b) Autonomous}

The WhatsApp application allows students to become independent students because they can learn independently. And they can practice using their language to share ideas without limited space and time in class. The role of the teacher as a facilitator is important to ensure that students have adequate language exposure and teaching guidance. It is also believed that autonomous learning using WhatsApp creates responsible students.

\section{c) Enthusiasm}

WhatsApp can also increase student enthusiasm in learning. Because they can comment on each other use their language and increase their interest in writing.

\subsection{Positive attitude: Love English}

Students' responses and negative attitudes towards English are only because they rarely communicate in English. However, once they have experienced using the target language in the natural process by using the media that they normally use namely WhatsApp, they may be impressed and may encourage themselves to practice it regularly.

In this article, the teacher will implement three phases of teaching English using WhatsApp application. So, hoping this method can increase vocabulary for students and meaningful to apply. Teaching procedures used by researchers/teachers when conducting teaching and learning activities in the class are divided into three:

\section{a) Pre-Activity}

In class, before starting lessons and using WhatsApp as a medium, the teacher must ensure tools or instruments for complete teaching and learn such as markers, erasers, laptops, projectors and cellphones as well. The teacher also makes sure the whiteboard is clear and divides the whiteboard into two or more parts so that it can arrange the material written on the board neatly arranged. And then the teacher must prepare; the first is greetings because good teachers don't forget this step to start the lesson.

The second step is to ask about the condition, after saying hello, usually ask about the condition of your students to make a close relationship with them and then ask the chairman to lead the prayer before starting the lesson. The third is checking attendance list; this is a step to find out who students are present or not present in your class. Fourth is to provide motivation, this is an important step, and the teacher must have the skills to motivate students so that students have more motivation to learn English. The teacher must also be able to provide the motivation that is suitable for each level of class students will be taught. The last teacher gives ice breaking or warmup related to the material to be taught to students. After that, the teacher gives several questions to activate the students' background knowledge to help them understand what information they will learn.

Then the teacher gives instructions to students who can answer questions to write on the board which has been divided into several parts by the teacher and teacher directs students to write starting from the top of the whiteboard from left to right so that the material written is neatly arranged and can be understood by students other. Even though the technique of asking a few questions before starting the lesson is not always appropriate to be applied in the classroom but this method can help to activate the background of students' knowledge about students before starting the lesson.

\section{b) Main Activity}

Before moving to the next step, there are two ways that can be applied by the teacher to use the WhatsApp application as a media, namely through independent and dependent conversations. In this step the teacher chooses the Independent Conversation method to be used in the class and provides an opportunity for students to issue and discuss the ideas they want to express in the WhatsApp group of classes that have been created and after that ask them to share what they have discussed in the WhatsApp group is written and oral.

In this step, the teacher starts the presentation, before forming a WhatsApp group the teacher has asked the students what they got from the warm-up given by the teacher related to the topic and gives instructions to students to write their knowledge pertaining to the item on the board to lure students into being active in the classroom.

The teacher also provides appreciation, such as saying thank you or giving applause to students who can answer questions to increase self-confidence and motivation of students to be active in class. After that the teacher begins to give a clear example of the topic namely "describing people", forming a WhatsApp group, and asking students to name any vocabulary that can be used to describe the people in the WhatsApp group that have been created. And then the teacher gives some questions to students about what should be mentioned in describing people and then asks students to give some examples of how to describe people verbally and write down any vocabulary that can be used in describing people on the board in front of the class. 
The last in this step is the teacher asks students to conclude about the material they are learning to know their ability to understand the topic given, after which the teacher provides a follow-up to concluding the material to make students better understand the material.

\section{c) Post Activity}

This phase is the last step; in this step, the teacher also needs to apply the right techniques to make teaching and learning activities meaningful in the closing part of this stage. After students discuss in the WhatsApp group and conclude the material, it's time for the next step to practices, the teacher gives several tests to students with clear instructions and still gives follow- up actions for students after completing the test. This test is also useful to find out how well students can learn by using the WhatsApp application as a medium to discuss the material that has been given. And after giving the evaluation, in this step is the teacher evaluation that asks students to correct the exam to make the class more active jointly. And then after that, the teacher gives an expansion such as giving students gifts or homework related to the material they have learned to make students also actively study at home and remember their memories of the lesson. And in this gift or homework, the teacher uses the conversation dependent method and asks students to gather their assignments through WhatsApp groups in which the teacher also participates.

Finally, the teacher also asks students what conclusions from the material they have learned, and then the teacher still gives conclusions about the content before closing the lesson to ensure all students understand the material. In connection with all the information above, there are three main phases of teaching and learning activities in implementing the WhatsApp application as a learning media. Each step is designed in several ways that are expected to encourage students to become active learners and viewers so that the methods can be meaningful ways for students to improve their English.

\section{Conclusion}

The use of the WhatsApp application as a medium in teaching English in EFL classrooms is a new thing in the world of education. And if the use of the WhatsApp application can be developed better to support teaching English in EFL classrooms, it will further improve students' English language skills in four aspects, namely, speaking, writing, reading, and listening. Because WhatsApp has many advantages that support learning, this application can be used to send text messages, download and upload images or videos, send voice messages, and so on.
In this case, the teacher as a facilitator must also be able to use WhatsApp use according to the needs of students in the classroom, so students become active students. So, the teacher must be able to run several effective ways so that the use of the WhatsApp application in the classroom can take place well and support students learning activities.

There are two ways that can be applied by the teacher; Dependent on Conversations and Independent Conversations. In this article the method of learning is classified into three phases to provide a more meaningful way for teachers to apply the use of WhatsApp applications, first Pre-Activity, in this phase the teacher must have mental and physical preparation and before starting the lesson say hello, ask conditions, give motivation, checking attendance lists, and giving warmth to students. The second phase is the main activity, in this phase, the teacher asks students about what they know based on the warmth that the teacher has given, and then gives an explanation of the material and starts applying the WhatsApp application as a medium of teaching. Then the last Post-Activity phase, in this step as part of the activity before closing the lesson, after students have had discussions through WhatsApp groups and evaluated the results of future class discussions hoping to understand and conclude the material, the teacher gives several tests and corrects together to make students more active and then the teacher also provides expansion before closing the lesson such as giving students homework related to the material and the teacher gives conclusions as well.

\section{References}

Andriani, R. (2016). Improving Students' Vocabulary Mastery using Interactive Multimedia. ELTLectura, 3(1).

Burd, B. A., \& Buchanan, L. E. (2004). Teaching the teachers: teaching and learning online. Reference Services Review, 32(4), 404-412.

Fisher, P. J., Bates, A., Gurvitz, D., \& Blachowicz, C. L. (2013). Vocabulary instruction: Struggling readers becoming word wizards. In SchoolBased interventions for struggling readers, K-8 (pp. 165-182). Emerald Group Publishing Limited.

Graves, M. F. (2000). A vocabulary program to complement and bolster a middle-grade comprehension program. Reading for meaning: Fostering comprehension in the middle grades, 116-135.

Hamad, M. M. (2017). Using WhatsApp to Enhance Students' Learning of English Language" Experience to Share". Higher Education Studies, 7(4), 74-87. 
Hamuddin, B. (2016). Using blog to Promote English Skills for EFL Students: The Students' Perception. ELT-Lectura, 3(2).

Hwang, S. O., Piazza, C. L., Pierce, M. J., \& Bryce, S. M. (2011). "My heart wants to say something": exploring ELL vocabulary use through e-mail. Multicultural Education \& Technology Journal, 5(1), 19-38.

Kheryadi, K. (2018). The Implementation of "WHATSAPP" as a Media of English Language Teaching. Loquen: English Studies Journal, 10(2), 1-14

Kruger, H., Drevin, L., \& Steyn, T. (2010). A vocabulary test to assess information security awareness. Information Management \& Computer Security, 18(5), 316-327.

Kuraedah, S., Gunawan, F., Wekke, I. S., \& Hamuddin, B. (2018, July). Learning Environment Construction in Islamic Higher Education: Connecting the Puzzles of Ideas. In IOP Conference Series: Earth and Environmental Science (Vol. 175, No. 1, p. 012107). IOP Publishing

Kurniawan, K., Andriani, R., \& Kasriyati, D. (2017). Pengembangan Media Animasi Untuk Pembelajaran Bahasa Inggris Sekecamatan Rumbai Kota Pekanbaru. Dinamisia: Jurnal Pengabdian Kepada Masyarakat, 1(1), 68-73.

La Hanisi, A., Risdiany, R., \& Sulisworo, D. (2018). The use of WhatsApp in collaborative learning to improve English teaching and learning process. International Journal of Research, 7(1), 29-35.

McGrail, E., McGrail, J. P., \& Rieger, A. (2016). Learning Language and Vocabulary in Dialogue with the Real Audience: Exploring Young Writers' Authentic Writing and Language Learning Experiences. In Writing Instruction to Support Literacy Success (pp. 117-135). Emerald Group Publishing Limited.

Molenda, H. R., \& James, D. R. (1982). Instructional Media and The New Technology of Instruction. Canada: John Wiley \& Son.

Mwakapina, J. W., Mhandeni, A. S., \& Nyinondi, O. S. (2016). WhatsApp mobile tool in second language learning: Opportunities, potentials and challenges in higher education settings in Tanzania.

Normore, A. H., \& Paul, Doscher, S. (2007). Using media as the basis for a social issues approach to promoting moral literacy in university teaching. Journal of Educational Administration, 45(4), 427-450.
Seipel, B. E. (2011). The role of implicit learning in incidental vocabulary acquisition while reading.

Vermeer, A. (2001). Breadth and depth of vocabulary about L1/L2 acquisition and frequency of the input. Applied Psycholinguistics, 22(2), 217234.

Wekke, I. S., Yandra, A., \& Hamuddin, B. (2017, December). Learning Strategy in Class Management: A Reflection from Manado Case. In IOP Conference Series: Earth and Environmental Science (Vol. 97, No. 1, p. 012053). IOP Publishing. 